\title{
Revista Brasileira de Psiquiatria
} RBPPsychiatry

\section{Patients with eating disorders (ED) treated with Zonisamide}

\section{Pacientes com transtornos alimentares (TA) tratados com Zonisamida}

\begin{abstract}
Dear Editor,
We would like to communicate our experience in patients with eating disorders (ED) treated with Zonisamide, a novel antiepileptic drug of the methane-sulfonamide group. This drug is rapidly absorbed in the gastrointestinal tract and it binds proteins moderately. Zonisamide is thought to act over voltage sensitive sodium channels and on T-type calcium channels. Moreover, Zonisamide alters the metabolism of glutamate, GABA, dopamine, serotonin, acetylcholine and carbonic anhydrase. The use of anticonvulsants in patients with ED is a common practice, due to their efficacy on weight and impulsive behaviour. ${ }^{1,2}$ The way they work is unknown: probably they act directly via general effect on pathological impulsivity thanks to their action on neurotransmitter systems. For this reason we think that Zonisamide, due to its properties, may be effective not only on binging behaviour but also in reducing self-injury in patients with Bulimia Nervosa (BN) and Binge Eating Disorder. ${ }^{3}$ Zonisamide was added to other medications up to the maximum dose of $300 \mathrm{mg}$ and a longitudinal analysis was performed at 3 months and after a year. The $80 \%$ of the patients was under treatment with fluoxetine and there was not modification of the pharmacological treatment during the follow-up. The sample consisted of seventeen females patients: see description in Table 1. Primary outcome measure was binging frequency. Secondary outcomes were Body Mass Index (BMI), Clinical Global Impressions-Severity of Illness Scale (CGI-SI) and self-injury. Ten of the seventeen patients concluded the 12 month follow-up; the other seven patients discontinued for the following reasons: increase of ocular pressure $(n=1)$, increase of serum creatinine levels $(n=1)$; paranoid symptoms $(n=1)$ and withdrawal of the follow-up $(n=4)$. Due to the little sample size only BMI and CGI-SI were analysed at endpoint visit. The statistical analysis evaluated treatment-by-time interaction effect on BMI, binging behaviour, self-harming and the CGI-SI. A 5.72\% reduction of $\operatorname{BMI}(p=0.02)$, a decrease in binges $(p=0.01)$ and self-harming episodes $(p=0.03)$ and a significant improvement in CGI-SI $(p<0.00001)$ were observed after 12 weeks of treatment. Improvement in $\mathrm{CGI}-\mathrm{SI}$ was prolonged a year after $(\mathrm{p}<0.00001)$, not the improvement of BMI (0.19). According to our review this is the first study that evaluates the efficacy of Zonisamide
\end{abstract}

Table 1 Characteristic of the sample

\begin{tabular}{|c|c|c|c|}
\hline \multicolumn{2}{|c|}{ Outcome $e^{n+\cdots+m}$} & \multirow{2}{*}{$\frac{\text { Frequency }}{3}$} & \multirow{2}{*}{$\begin{array}{c}\text { Percentage } \\
17.6\end{array}$} \\
\hline Diagnose Axis I & Bulimia Nervosa & & \\
\hline & Binge eating Disorder & 14 & 82.4 \\
\hline \multirow[t]{2}{*}{ Drug abuse } & No & 15 & 88.2 \\
\hline & Yes & 2 & 11.8 \\
\hline \multirow[t]{2}{*}{ Diagnose Axis II } & None & 8 & 47.1 \\
\hline & Border-line personality & 9 & 52.9 \\
\hline \multirow{2}{*}{$\begin{array}{l}\text { Binging behavior: } \\
\text { less than } 3 \text { binges per week }\end{array}$} & Baseline & 2 & 11.8 \\
\hline & 3 months follow-up* & 6 & 35.3 \\
\hline \multirow{2}{*}{$\begin{array}{l}\text { Binging behavior: } \\
\text { between 3-6 binges per week }\end{array}$} & Baseline* & 7 & 41.2 \\
\hline & 3 months follow-up" & 3 & 17.6 \\
\hline \multirow{2}{*}{$\begin{array}{l}\text { Binging behavior: } \\
\text { more than } 6 \text { binges per week }\end{array}$} & Baseline ${ }^{*}$ & 8 & 47.1 \\
\hline & 3 months follow-up" & 2 & 11.8 \\
\hline \multirow[t]{2}{*}{ Self-harming } & Baseline ${ }^{*}$ & 9 & 52.9 \\
\hline & 3 months follow-up" & 2 & 11.8 \\
\hline \multicolumn{2}{|l|}{ Outcome } & Mean & Range/SD \\
\hline \multicolumn{2}{|l|}{ Age } & 32.7 & $20-43 / 7.2$ \\
\hline \multicolumn{2}{|l|}{ Ilness duration } & 13.8 & $2-20 / 6.7$ \\
\hline \multirow[t]{3}{*}{ CGI-SI"' } & Baseline ${ }^{*}$ & 4.2 & $3-6 / 0.75$ \\
\hline & 3 months follow-up" & 2.7 & $2-4 / 0.64$ \\
\hline & 12 months follow-up & 3 & $2-4 / 0.89$ \\
\hline \multirow[t]{3}{*}{ BMI' } & Baseline & 33 & $20-56.6 / 10.7$ \\
\hline & 3 months follow-up" & 33 & $19-55 / 11.6$ \\
\hline & 12 months follow-up & 32 & $19-44 / 10.4$ \\
\hline \multirow[t]{2}{*}{ Zonisamide dosage } & Baseline & 167.64 & $50-300 / 72.7$ \\
\hline & 3 months follow-up & 195 & $50-300 / 72.2$ \\
\hline
\end{tabular}

"Total sample: 17; **Total sample: 11; ***Total sample: $10 ;{ }^{* * * *}$ Clinical Global Impression Severity Illness; ${ }^{* * * * *}$ Body Mass Index. ${ }^{* * * * * *}$ Linear mixed models were used to analyze the evolution of outcome measures at different time points during treatment. 
in subjects with BN: the most interesting observation was that Zonisamide was clinically effective to control self-injury. In addition, we found a significant correlation between axis II diagnose and self-harm indicating that Zonisamide is more efficacious on patients with border-line co-morbidity. It is reported that Zonisamide is effective for the long term treatment. ${ }^{4}$ In our study the improvement of BMI found at endpoint visit was not significant: this fact might be attributable to the high attrition $(35,3 \%)$ that we reported, comparable to the attrition rate reported in McElroy 's study. ${ }^{5}$ As far as we know the increase of ocular pressure (most serious adverse event reported) has not been described in studies concerning Zonisamide's tolerability. To conclude we think that Zonisamide is useful for treating overweight in BED and BN patients and may be an option for controlling other impulsive behaviours in patients with ED.

\section{Ester Idini, Imma Buj-Alvarez, Josep Pifarre-Paradero; Stella Rodriguez-Picasso, Ester Castan-Campanera Department of Psychiatric Santa Maria Hospital, Lleida, Spain}

\section{Disclosures}

Ester Idini

Employment: Department of Psychiatric, Santa Maria Hospital, Lleida, Spain.

Imma Buj-Alvarez

Employment: Department of Psychiatric, Santa Maria Hospital, Lleida, Spain.

Josep Pifarre-Paradero

Employment: Department of Psychiatric, Santa Maria Hospital, Lleida, Spain.
Stella Rodriguez-Picasso

Employment: Department of Psychiatric, Santa Maria Hospital, Lleida, Spain. Ester Castan-Campanera

Employment: Department of Psychiatric, Santa Maria Hospital, Lleida, Spain.

* Modest

** Significant

*** Significant: Amounts given to the author's institution or to a colleague for research in which the author has participation, not directly to the author.

\section{References}

1. McElroy S, Guerdjikova A, Martens B, Keck P, Harrison JR. Role of Antiepileptic Drugs in the Management of Eating Disorders. CNS Drugs. 2009;23(2):139-56.

2. Gadde KM, Franciscy DM, Wagner HR 2nd, Krishan KR. Zonisamide for weight loss in obese adult: a randomized controlled trial. JAMA. 2003;289:1820-5.

3. Monteleone P, Brambilla F, Bortolotti F. Serotonergic dysfunction across the eating disorders: relationship to eating behaviour, purging behaviour, nutritional status and general psychopathology. Psychol Med. 2000;30:1099-110.

4. Ohtahara S, Yamatogi Y. Safety of Zonisamide therapy: prospective follow-up survey. Seizure. 2004;4(S1):S50-5.

5. McElroy S, Kotwal R, Guerdjikova Al, Welge JA, Nelson EB, Lake KA. Zonisamide in the treatment of Binge-Eating disorder with obesity: A Randomized controlled trial. J Clin Psychiatry. 2006;67:1897-1906. 